\title{
CMA GC: Seniors' health comes first for most Canadians
}

$C$ $M A J$ is reporting from the 149th Annual Meeting and General Council of the Canadian Medical Association (CMA), being held in Vancouver Aug. 21-24. Issues to be discussed this year include drug shortages, a new Health Accord, social media and climate change.

\section{Seniors' health comes first for most Canadians}

Most Canadians want seniors' health to take top priority under a new Health Accord, but few realize that new funding talks are underway, according to the 16th Annual National Report Card on Health Care by the CMA. Only $15 \%$ of Canadians polled by Ipsos Reid for the report were aware that the federal government is renegotiating how it provides health funding to provinces and territories. Even so, most people agreed on what a new accord should include.

Read full article

\section{Experience guides CMA}

\section{president-elect on Health Accord}

Dr. Granger Avery's tenure as president of the CMA will begin as health care stakeholders finalize their positions in advance of talks with Ottawa and the provinces on a new national Health Accord. Avery, who worked on the previous accord, says he's buoyed by the Liberal government's attitude after the Conservatives refused to discuss health care.

Read full article

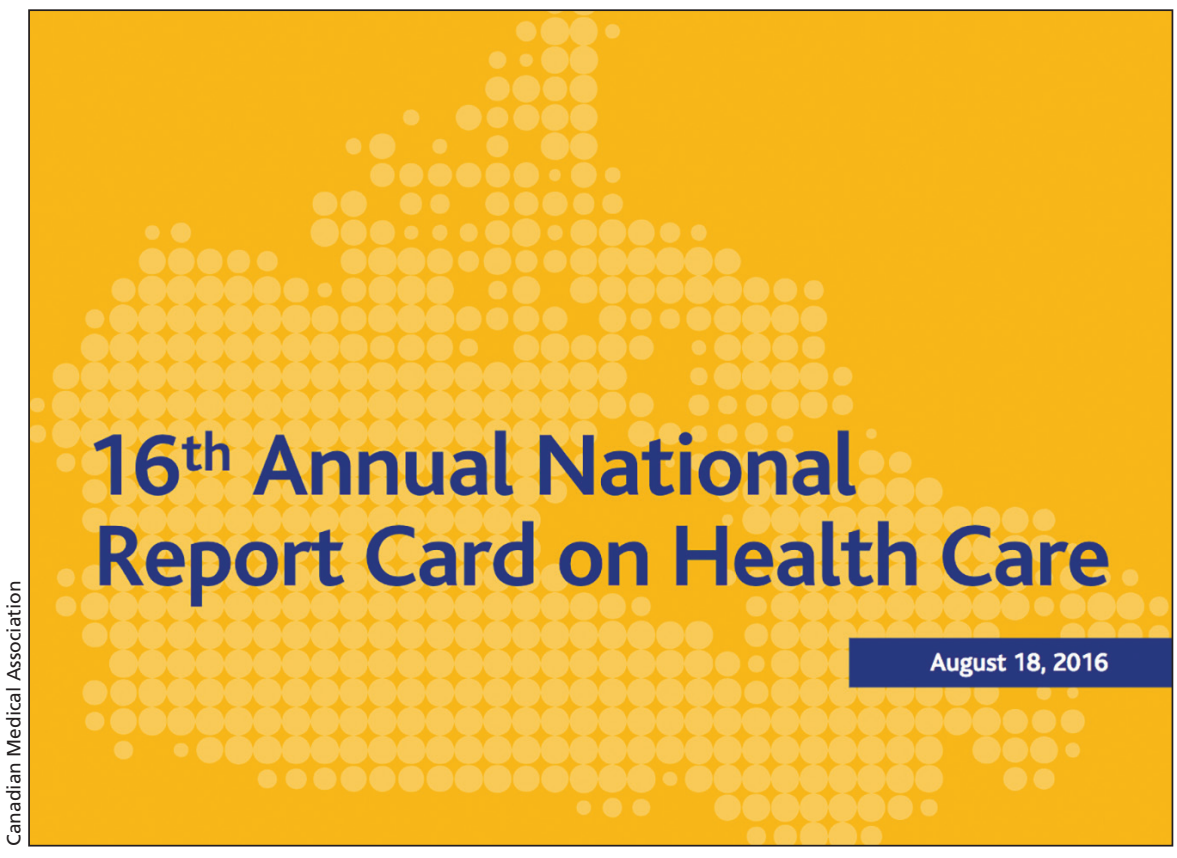

Most Canadians want a new Health Accord to prioritize seniors' health and prescription drug coverage, found a CMA-commissioned survey.

\section{A behind-the-scenes peek at being CMA president}

There are many kinds of busy. There is exam-week busy. There is two-jobsand-four-kids busy. And then there is CMA-president busy. "There were months when I was home only three or four days," said Dr. Cindy Forbes, who will soon finish her year-long stint as president of the CMA. But it's worth it, said Forbes. "It is a wonderful experience from a personal growth point of view, but also a wonderful opportunity for people who see the need for change and feel they can bring something to the table to improve the health of Canadians or improve the ability of physicians to look after patients."

Read full article
CMA President-Elect Dr. Granger Avery on pressing health topics

In an interview with $C M A J$, CMA President-Elect Dr. Granger Avery gave his thoughts on some of the pressing health issues facing Canada today. Read full article

\section{Dr. Cindy Forbes on biggest} health care issues of the past year There are many pressing health care issues in Canada. CMAJ asked outgoing CMA President Dr. Cindy Forbes about the biggest ones she worked on during her presidency.

Read full article

— Roger Collier, CMAJ

CMAJ 2016. DOI:10.1503/cmaj.109-5316 